\title{
Determination of the Effect of Cold Working Compression on Residual Stress Reduction in Quenched Aluminium Alloy 2219 Block
}

\author{
Abdulrahaman Shuaibu Ahmad1,2 - Wu Yunxin1,2,* - Gong Hai1,2 - Liu Lei2 \\ ${ }^{1}$ Central South University, College of Mechanical and Electrical Engineering, China \\ ${ }^{2}$ Central South University, State Key Laboratory of High-Performance Complex Manufacturing, China
}

\begin{abstract}
Residual stresses are induced in components during mechanical, thermal, machining, and plating operations. If not carefully considered in the design process, residual stress can be a significant factor in the failure of components, particularly when subjected to alternating service loads or corrosive environments. The induced residual stresses in three quenched aluminium alloy 2219 blocks were experimentally investigated, and cold working compression was performed at room temperature to relieve the stresses. High residual stresses were observed in the blocks after quenching. Therefore, their reduction became necessary to improve the tolerance of machined parts and avoid their failure. The samples were cold-worked at various compression ratios (CR). The residual stresses were significantly relieved, and it was discovered that $2 \% \mathrm{CR}$ offers a considerable effective reduction in the residual stress. Relieving these residual stresses will improve the reliability of the samples and the components to be manufactured.
\end{abstract}

Keywords: residual stress, aluminium alloy 2219 , quenching, cold working compression

Highlights

- Residual stresses were analysed after quenching the 2219 aluminium samples.

- $\quad$ The samples were cold compressed using various $C R$ after quenching.

- $\quad$ The residual stress relieving efficiencies of the selected $C R$ were compared.

- The final results show that $2 \% \mathrm{CR}$ is the most effective in residual stress reduction.

\section{O INTRODUCTION}

Residual stresses are locked-in stresses that remain in solid materials after the removal of the external cause of stresses [1]. Residual stresses are induced in components during most manufacturing processes, such as material deformation, heat treatment, machining, or processing operations that transform the shape or change the properties of the material [1]. They develop when a body undergoes inhomogeneous plastic deformation or is exposed to a non-uniform temperature distribution, such as in the case of welding, warm forming, casting, and quenching processes [2] to [4].

A material's ability to resist fatigue, and crack initiation and propagation at ambient temperature, brittle fracture, machining distortion, and corrosion cracking is adversely affected by residual stresses [3] and [5] to [7]. These effects regularly cause significant costs of repairs or replacement of parts [5]. Analysis of residual stresses is considered as one of the necessary steps in the design of structural elements and components, which aid in predicting their reliability under different loading conditions during operation [6]. Extensive studies revealed that the fatigue strength of welded elements is drastically reduced due to high residual stresses induced at the weld bead and heat-affected zone (HAZ) [8] and [9]. Webster et al. reported that residual stress, which can be in excess of the yield strength of the material, could develop at the HAZ: is the region near the weld zone that is not melted during welding, but its properties have been severely altered due to the effect of the welding torch [10] to [12]. Therefore, the effects of residual stresses are comparably the same as that of stress concentration. Residual stresses are now considered one of the leading factors influencing the properties of metallic materials. Thus, they should be given due consideration during the design and manufacturing of parts and components. Due to their self-equilibrating nature, the presence of residual stresses may not be readily evident, and so they may not be carefully considered during engineering design. However, they are stresses and must be given due consideration in the same way as stresses due to external loading.

The hole-drilling technique based on ASTM E-837-13a standard [13] is used to measure the residual stresses, as presented in this paper; the residual stresses cannot be measured directly [14]. Usually, the elastic strains resulting from the relieved stresses initially present at hole position are measured directly, then, the residual stresses can be computed using mathematical relations. 
Aluminium alloy 2219 is the material used in this experiment; it is a commonly used material for the manufacture of components used for hightemperature applications, high strength weldment, supersonic aircraft structures as well as space industry applications [15] to [17]. It requires strengthening through heat treatment before the parts mentioned above are manufactured; during the process, high residual stresses are induced. Therefore, their reduction becomes necessary to improve the reliability of the manufactured parts.

The techniques for relieving residual stresses are mainly categorized into the thermal methods (i.e., heat treatment and mechanical methods, which include cold working compression) stretching, and some other mechanical surface treatment techniques, etc. [18] to [20]. Based on experimental and manufacturing outcomes, stretching appears to be more effective in relieving residual stresses, but it is practically impossible to stretch an unsymmetrical and nonrectangular shaped component due to handling difficulties and non-symmetrical loading. As such, compression processes are favourably considered and commonly employed [2]. Hence, compression is mainly applied to parts having simple geometries and parallel surfaces. Cost-effectiveness, availability, and accessibility to equipment also decides the technique to be used for relieving residual stresses. Muammer et al. compared the compression and stretching techniques of residual stress reduction for quenched aluminium 7050 [2]. Up to $90 \%$ reduction in residual stresses for $2 \%(\mathrm{CR})$ was reported.

A quenching experiment was performed in the first section of this paper, and the residual stresses induced in three quenched aluminium alloy 2219 blocks are determined using the hole-drilling method. In the second section, the cold working compression for relieving the induced residual stresses was carried out; different CRs were applied for each sample. Moreover, the residual stresses were measured for the compressed Al 2219 blocks. Finally, the x and $\mathrm{y}$ components residual stresses before and after compression were compared, and the average relieved residual stresses for each selected CR was also presented.

\section{QUENCHING EXPERIMENT}

Three samples of an aluminium alloy 2219 block of the same dimensions $200 \mathrm{~mm} \times 160 \mathrm{~mm} \times 130 \mathrm{~mm}$ were heated to an elevated temperature of $540{ }^{\circ} \mathrm{C}$ and held for 4 hours in the furnace; the samples were then quenched in the water of $40{ }^{\circ} \mathrm{C}$ for 10 minutes. The quenching conditions are shown in Table 1. The blocks were allowed to cool to room temperature before the residual stress measurement was carried out, Figs. 1 and 2 show the samples prepared for heat treatment.

Table 1. Conditions for the heat treatment

\begin{tabular}{lcc}
\hline Parameters & Symbol & Value \\
\hline Blocks temperature before quenching & $T_{0}$ & $540^{\circ} \mathrm{C}$ \\
\hline Quenching medium temperature & $T_{t}$ & $40^{\circ} \mathrm{C}$ \\
\hline Blocks temperature after quenching & $T_{1}$ & $40^{\circ} \mathrm{C}$ \\
\hline Quenching duration & $t$ & $600 \mathrm{~s}$ \\
\hline
\end{tabular}

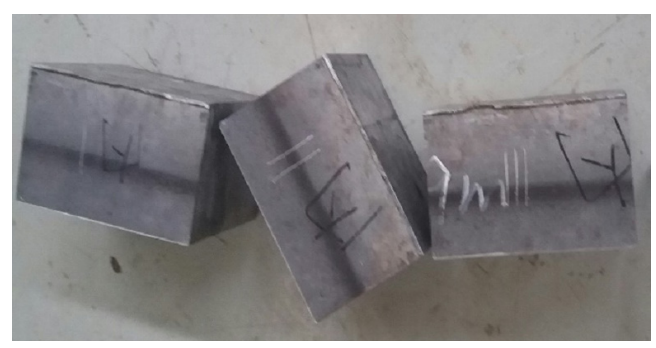

Fig. 1. Aluminum 2219 block samples

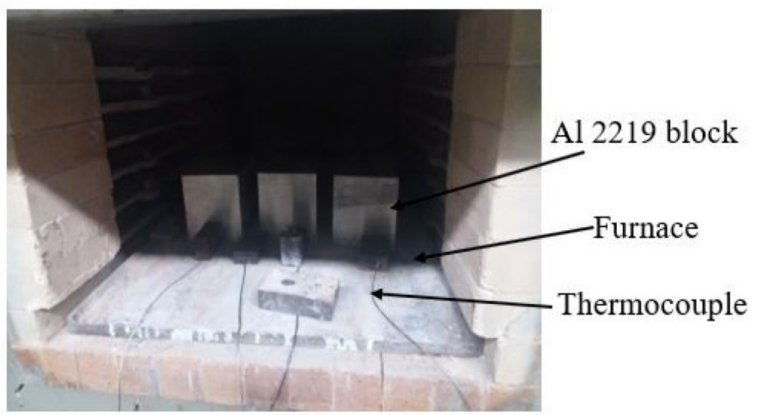

Fig. 2. Samples prepared in a furnace

\subsection{Material Properties}

The average density of the $\mathrm{Al} 2219$ used in this work is $2820 \mathrm{~kg} / \mathrm{m}^{3}$ [21], the temperature-dependent properties of the Al 2219 shown in Figs. 3 to 7 were measured at the Nonferrous, Advanced Structure Materials and Manufacturing Research Center, Central South University, China.

The residual stresses induced during the quenching process were then measured using the hole - drilling method base on the uniform stress method.

\subsection{Residual Stress Measurement using Hole-drilling Technique}

Based on the ASTM E837-13a standard [13], the holedrilling measurement can be performed using the 
uniform or non-uniform stress method to examine the residual stresses.

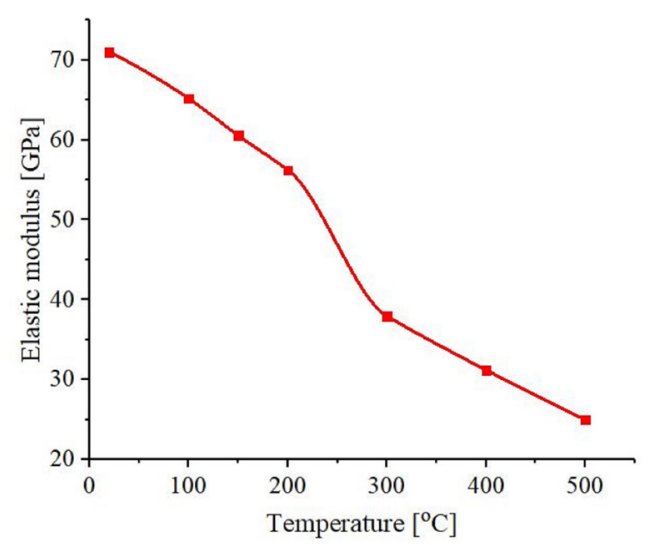

Fig. 3. The elastic modulus of aluminum 2219; Poisson ratio $=0.33$ at all temperatures

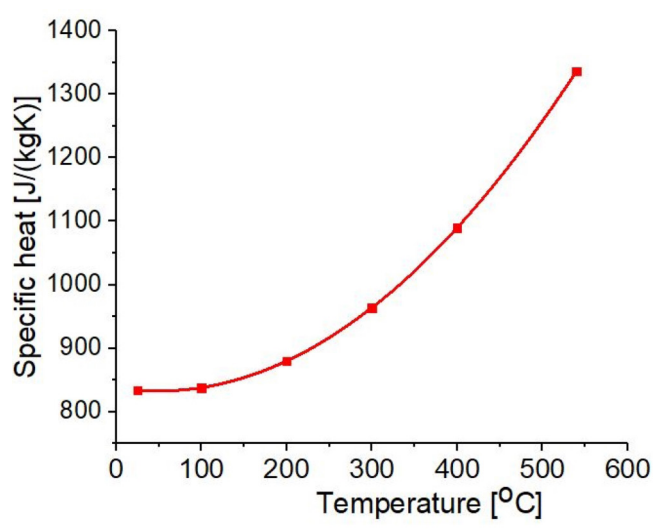

Fig. 4. Specific heat of aluminum 2219

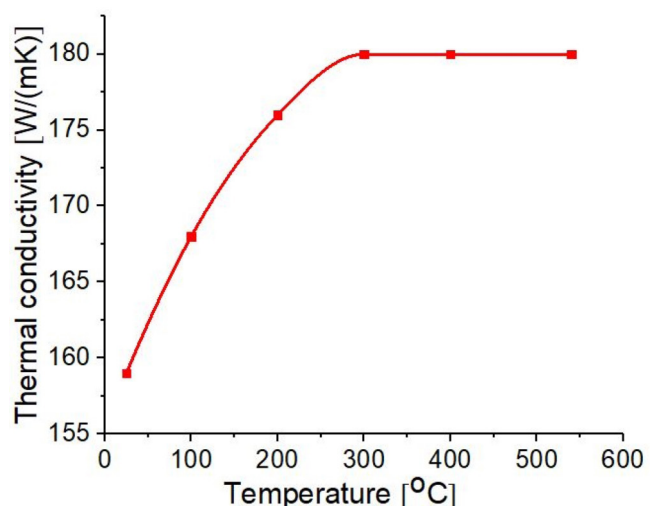

Fig. 5. The thermal conductivity of aluminum 2219

(a) Uniform stress method: In this approach, the in-plane stresses are considered uniform throughout the drilled hole depth for material whose thickness is larger in comparison with the strain gage circle and hole diameter. Therefore, a blind hole can be drilled, and the strain data will be recorded after reaching the required depth (maximum of $2 \mathrm{~mm}$ ).

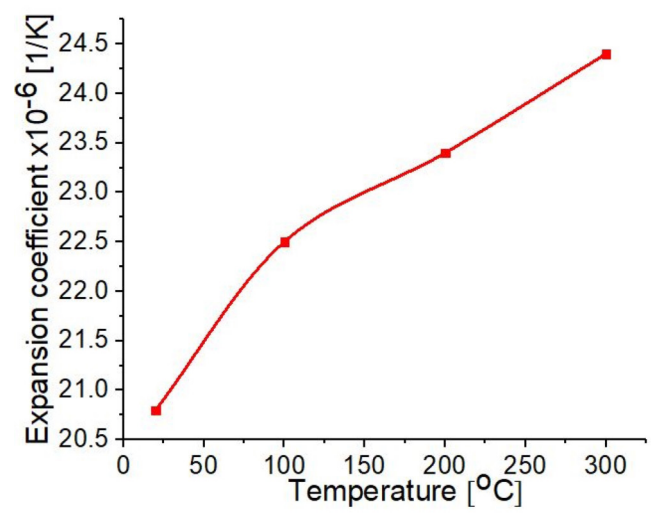

Fig. 6. Thermal expansion of aluminum 2219

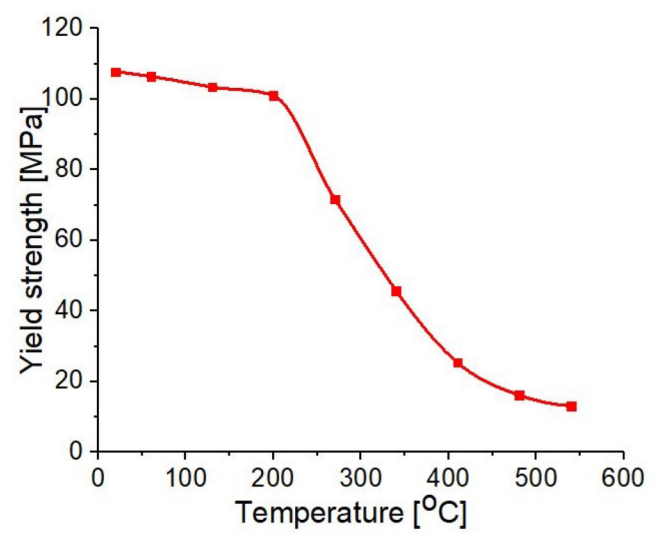

Fig. 7. The yield stress of aluminum 2219; plastic strain $=0$, at the given temperature range

(b) Non-uniform stresses method: in this approach, the in-plane stresses are considered to vary with the depth of the hole. Therefore, an incremental hole drilling method is used; the hole is drilled in steps, depending on the workpiece thickness and the strain gage parameters, and the strains are recorded after every increment [14]. In this paper, considering the thickness of the samples $(130 \mathrm{~mm})$, the strain gage circle diameter $(5.13 \mathrm{~mm})$, the hole diameter $(1.8 \mathrm{~mm})$, and the hole depth $(2 \mathrm{~mm})$, which is a nearsurface region, the in-plane residual stresses and are considered to be uniform. Therefore, the uniform stress technique was adopted. It is evident that the residual stresses cannot be measured directly using this method, thus, the relieved strains which depends on the residual stresses that existed in the material originally within the drilled hole are determined directly. Therefore, the residual stresses at the drilledhole locations were evaluated from the relieved strains using the mathematical relations based on the linear 
elasticity theory as shown in Eq. (1) [15] and [22]. Fig. 8. Illustrates the in-plane stresses in $x$ and $y$ directions.

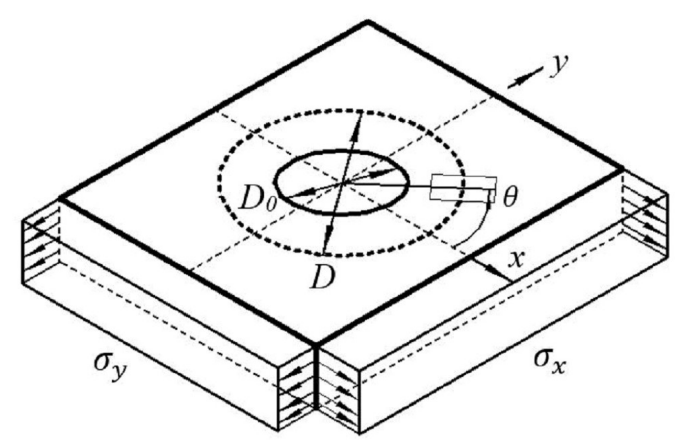

Fig. 8. Hole geometry and uniform stresses along $x$ and $y$ components [13]

$$
\begin{aligned}
\varepsilon= & \frac{\sigma_{x}+\sigma_{y}}{2} \frac{(1+\vartheta) \bar{a}}{E}+\frac{\sigma_{x}-\sigma_{y}}{2} \frac{\bar{b}}{E} \cos 2 \theta+ \\
& +\tau_{x y} \frac{\bar{b}}{E} \sin 2 \theta .
\end{aligned}
$$

Eq. (1) can also be written as

$$
\varepsilon=P \frac{(1+\vartheta) \bar{a}}{E}-Q \frac{\bar{b}}{E} \cos 2 \theta+T \frac{\bar{b}}{E} \sin 2 \theta,
$$

where

$$
P=\frac{\sigma_{x}+\sigma_{y}}{2}, \quad Q=\frac{\sigma_{y}-\sigma_{x}}{2}, \quad T=\tau_{x y} .
$$

In Eqs. (1) and (2), and are the "uniform" in-plane stresses and $\theta$ is the angle between the strain gage axis and the $x$ direction. The terms and are calibration constants that define the strain/stress sensitivity of the measurement. Their numerical values depend on the drilled-hole diameter and depth. $P, Q$ and $T$ are the combination stresses, and represents the Poisson ratio depending on the isotropic strains.

The combination stresses $P, Q$, and $T$ are corresponding to the combination strains $p, q$, and $t$. Therefore, Eq. (2) can be rewritten in terms of the combination stresses, and their corresponding combination strains as follows.

$$
\begin{gathered}
P=\frac{\sigma_{x}+\sigma_{y}}{2}=\frac{E}{(1+\vartheta) \bar{a}} p, \\
Q=\frac{\sigma_{y}-\sigma_{x}}{2}=\frac{E}{\bar{b}} q, \\
T=\tau_{x y}=\frac{E}{\bar{b}} t,
\end{gathered}
$$

where

$$
p=\frac{\varepsilon_{3}+\varepsilon_{1}}{2}, \quad q=\frac{\varepsilon_{3}-\varepsilon_{1}}{2}, \text { and } t=\frac{\varepsilon_{3}-2 \varepsilon_{2}+\varepsilon_{1}}{2} .
$$

The combination strains $p, q$, and $t$ in the Eq. (6) represent the isotropic, $45^{\circ}$ shear and axial shear strains, and they are calculated using the above equations. The stresses and are then evaluated using Eqs. (7), (8) and (9) below.

$$
\begin{gathered}
\sigma_{x}=P-Q, \\
\sigma_{y}=P+Q, \\
\tau_{x y}=T .
\end{gathered}
$$

Type A strain gage rosette with a circle diameter of $5.13 \mathrm{~mm}$ was used in this experiment, the axial strains were deducted directly from the strain gage output display, which were used to obtain all the required parameters using the above equations. Fig. 9 shows the layout of the type A strain gage rosette and Fig. 10 shows the workpiece with the rosette attached.

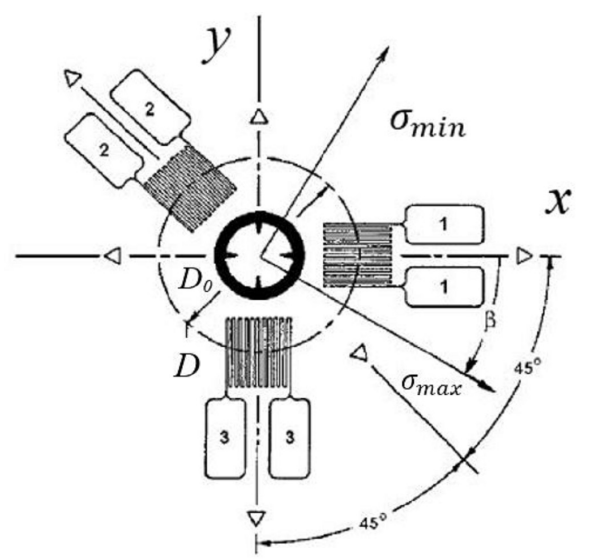

Fig. 9. Strain gage rosette layout [9], [13]

\subsection{Residual Stresses after Quenching}

The residual stresses measurement was carried out using the MTS3000 hole-drilling machine with drilling resolution of $5 \mu \mathrm{m}$, and drilling speed range of $0.03 \mathrm{~mm} / \mathrm{min}$ to $1 \mathrm{~mm} / \mathrm{min}$, the residual stresses at three various points on the surfaces of each sample were determined at drilling speed of $0.8 \mathrm{~mm} / \mathrm{min}$. Fig. 11 illustrates the selected positions on the workpieces and Fig. 12 shows the drill aligned to the rosette's centre during the measurement.

The relieved strains from the drilled hole at points 1, 2, and 3 were measured directly, then residual stresses are evaluated for each examined 
point, the results are shown in Tables 2 to 4 , and are also graphically presented in Figs. 13 to 15.

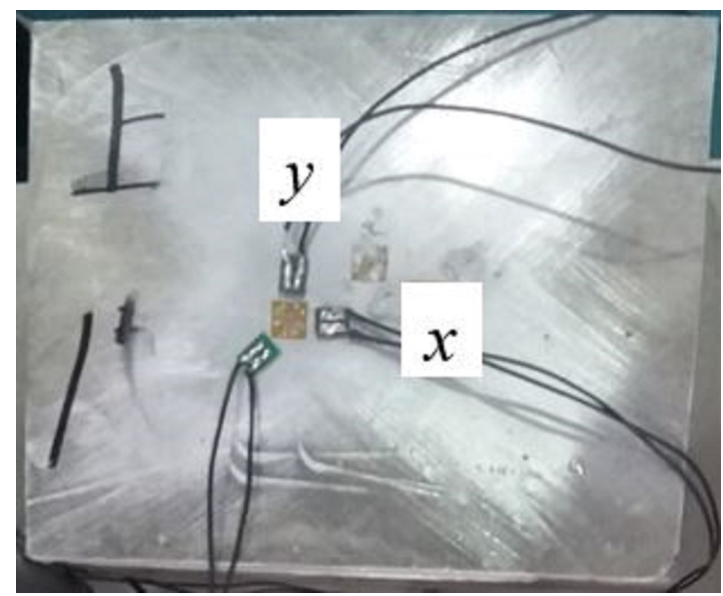

Fig. 10. Aluminum block sample with rosette attached

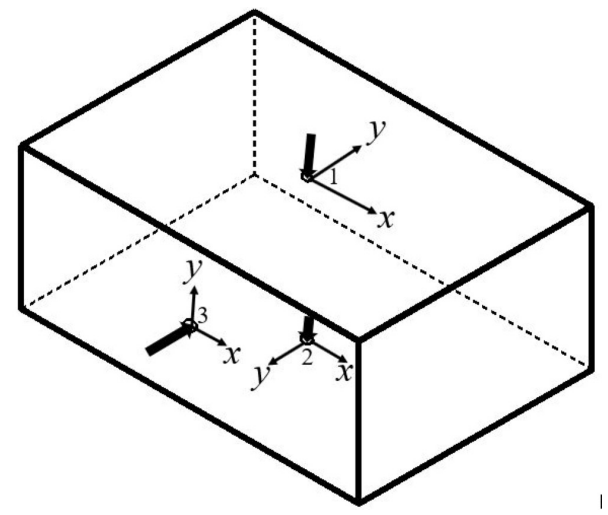

Fig. 11. Test points on the block

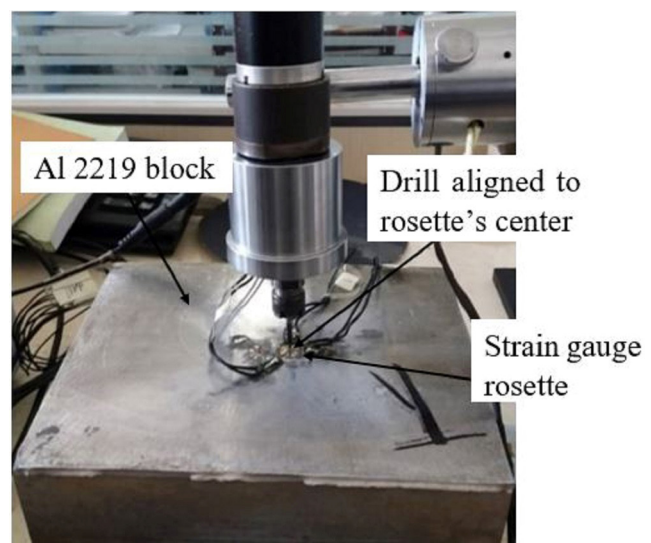

Fig. 12. Hole-drilling method of residual stress measurement

The quenching was performed in a stationary medium. Therefore, some parts of the workpiece, i.e. position 2 was first exposed to the quenching water before position 1; this can lead to variation in the residual stress distribution at positions 1 and 2 as the residual stresses are fully induced at the quenching stage.

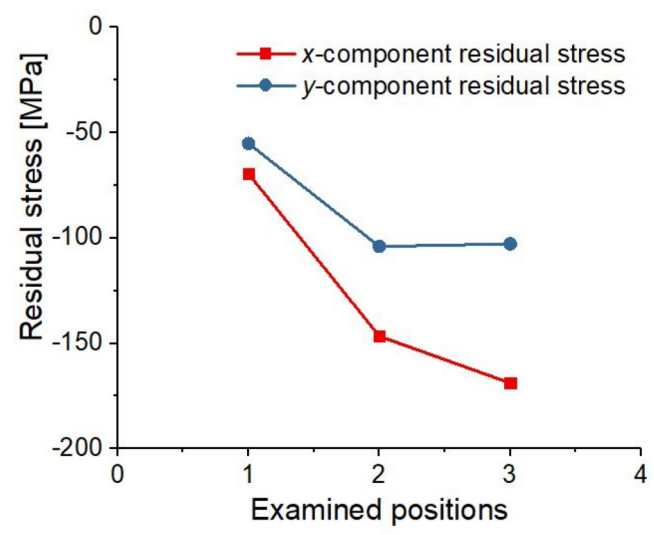

Fig. 13. Determined residual stresses (RS) in sample 1 after quenching

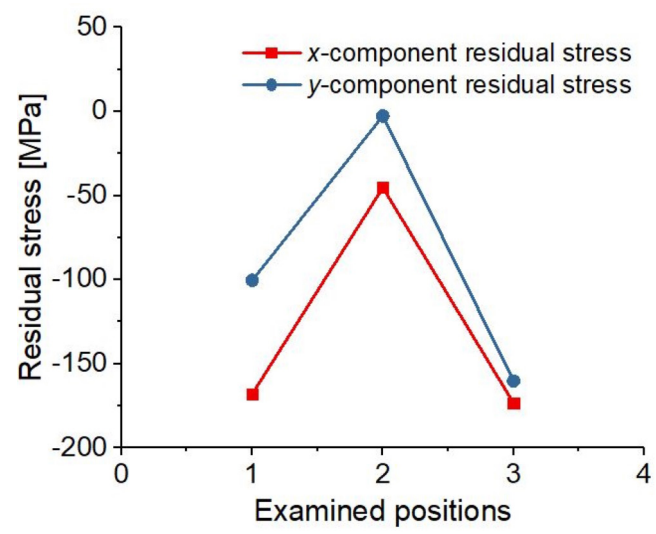

Fig. 14. Evaluated residual stresses in sample 2 after quenching

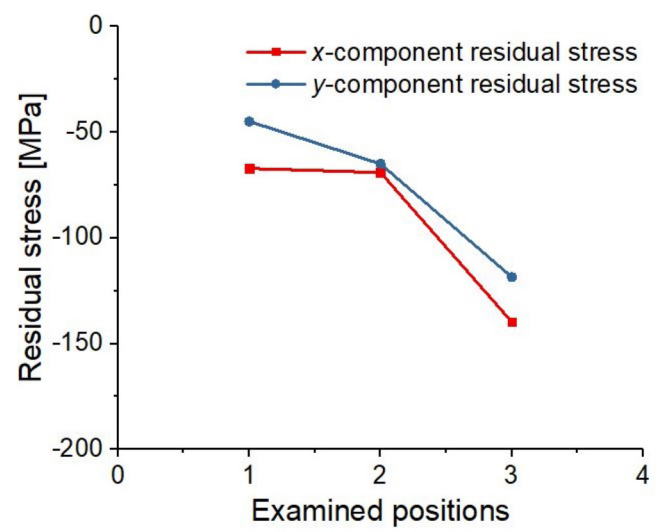

Fig. 15. Evaluated Residual stresses in sample 3 after quenching

The above results show the residual stresses induced due to the quenching at three locations on all the samples, the residual stresses are higher along $x$ component $\left(\sigma_{x}\right)$ of all the three samples, and they are 
compressive residual stresses. It was observed that, $\sigma_{x}=-168.89 \mathrm{MN} / \mathrm{m}^{2}$ is the highest residual stress in sample 1 , which is observed from point $3, \sigma_{x}=-173.41$ $\mathrm{MN} / \mathrm{m}^{2}$ is the highest residual stress in sample 2, and it is obtained from point 3 , and $\sigma_{x}=-139.81 \mathrm{MN} /$ $\mathrm{m}^{2}$ is the highest residual stress in sample 3 , and it is also determined from point 3 of the block. Therefore, relieving these stresses is very important to improve the reliability of the 2219 aluminium block and also to avoid the failure of manufactured components [23] to [25].

\section{RELIEF OF RESIDUAL STRESSES THROUGH COLD WORKING COMPRESSION}

Cold working compression process with a rigid flat die was performed on the three samples to reduce the residual stresses induced due to quenching. Fig. 16 shows the conceptual view of the process.

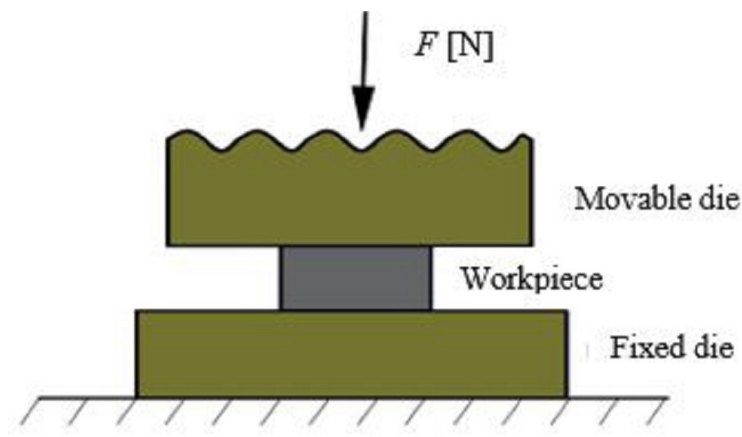

Fig. 16. The cold working compression process

Different CRs were selected for each sample to analyse the most efficient ratio in the residual stress reduction. The conditions for cold working compression applied to the samples are shown in Table 2 below.

Table 2. $C R$ for different samples

\begin{tabular}{ccc}
\hline S/N & Samples & CR [\%] \\
\hline 1 & Sample 1 & 2 \\
\hline 2 & Sample 2 & 3 \\
\hline 3 & Sample 3 & 4 \\
\hline
\end{tabular}

\section{RESULTS}

The three aluminium alloy 2219 blocks were compressed using the assigned CRs; the residual stresses in all the three blocks were measured using the hole-drilling method based on the uniform stress method after the cold working compression. Since the stresses are assumed to be uniform within the in-plane directions $x$ and $y$, residual stresses were measured at points corresponding to 1,2 , and 3 on all three blocks. The evaluated $\sigma_{x}$ and $\sigma_{y}$ are shown in Tables 3 to 5 and Figs. 17 to 19 .

Table 3. Residual stresses after cold working compression for sample 1

\begin{tabular}{lccc}
\hline & Examined locations & $\sigma_{x}\left[\mathrm{MN} / \mathrm{m}^{2}\right]$ & $\sigma_{y}\left[\mathrm{MN} / \mathrm{m}^{2}\right]$ \\
\cline { 2 - 4 } $2 \% \mathrm{CR}$ & 1 & 15.61 & 21.13 \\
\cline { 2 - 4 } & 2 & 14.65 & 16.28 \\
\cline { 2 - 4 } & 3 & -12.41 & 13.24 \\
\hline
\end{tabular}

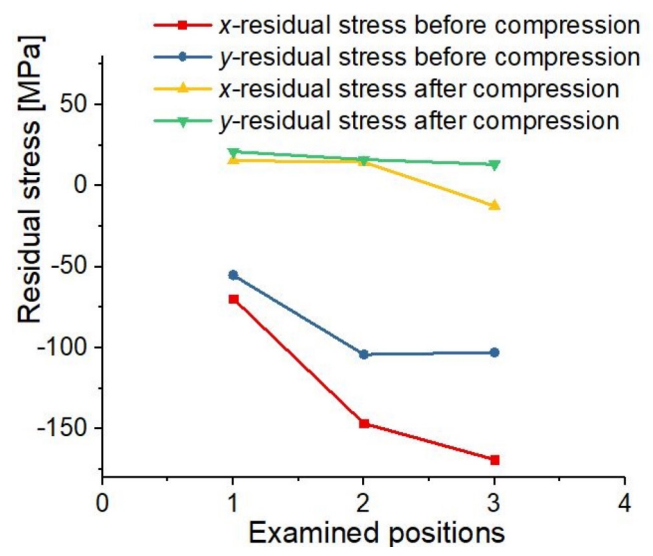

Fig. 17. Residual stresses before and after compression $(C R=2 \%)$ in sample 1

Table 4. Residual stresses after cold working compression for sample 2

\begin{tabular}{cccc}
\hline & Examined locations & $\sigma_{x}\left[\mathrm{MN} / \mathrm{m}^{2}\right]$ & $\sigma_{y}\left[\mathrm{MN} / \mathrm{m}^{2}\right]$ \\
\cline { 2 - 4 } $3 \% \mathrm{CR}$ & 28.93 & 34.57 \\
\cline { 2 - 4 } & 1 & -5.74 & 9.07 \\
\cline { 2 - 4 } & 2 & 23.78 & 53.39 \\
\hline
\end{tabular}

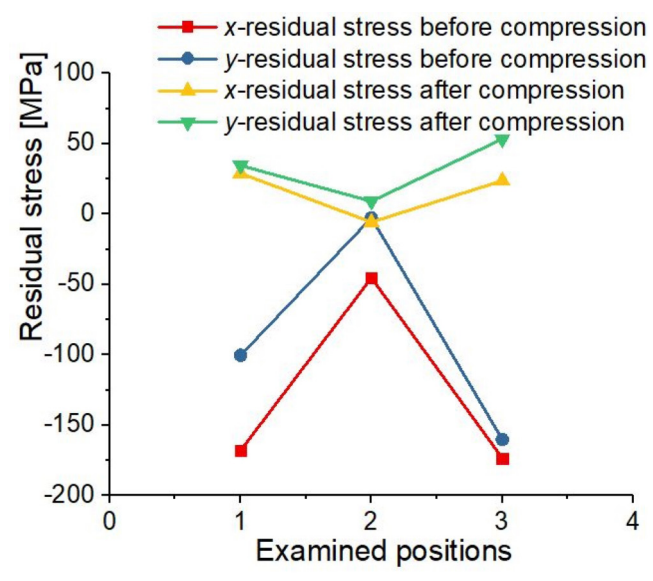

Fig. 18. Residual stresses before and after compression $(\mathrm{CR}=3 \%)$ in sample 2 
Table 5. Residual stresses after cold working compression for sample 3

\begin{tabular}{cccc}
\hline & Examined locations & $\sigma_{x}\left[\mathrm{MN} / \mathrm{m}^{2}\right]$ & $\sigma_{y}\left[\mathrm{MN} / \mathrm{m}^{2}\right]$ \\
\cline { 2 - 4 } $4 \% \mathrm{CR}$ & 6.81 & 15.42 \\
\cline { 2 - 4 } & 1 & 10.33 & 14.5 \\
\cline { 2 - 4 } & 2 & -29.22 & 10.22 \\
\hline
\end{tabular}

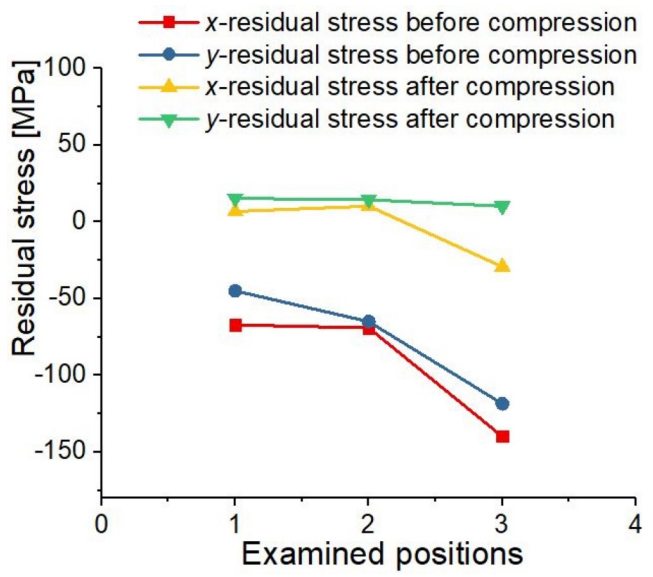

Fig. 19. Residual stresses before and after compression $(C R=4 \%)$ in sample 3

\section{DISCUSSION}

Based on the results obtained after the cold working compression, a significant reduction in the residual stresses was observed. As reported by Koç et al. [2] cold compression using $2 \%(\mathrm{CR})$ can relieve up to $90 \%$ of residual stresses induced due to quenching of Al 7050. As analysed, the same performance can be obtained using the same CR on Al 2219 specimen. Furthermore, comparing the three CRs used, $2 \%$ offers better stress reduction capacity than $3 \%$ and $4 \%$, but the same may not hold when applying the stretching technique to relieve the stresses. Also, much efficient reduction in the residual stress along $x$ component was observed for all the CR. Therefore, the stresses along $x$ were relieved by a higher percentage compared to $y$. The average relived stresses are summarized in Table 6.

Table 6. Average relieved residual stresses

\begin{tabular}{cccc}
\hline Samples & $\begin{array}{c}\text { Average residual } \\
\text { stress relieved [\%] } \\
x \text { component }\end{array}$ & $\begin{array}{c}\text { Average residual } \\
\text { stress relieved [\%] } \\
y \text { component }\end{array}$ & CR [\%] \\
\hline 1 & 86.8 & 81.87 & 2 \\
\hline 2 & 85.4 & 46.0 & 3 \\
\hline 3 & 84.7 & 51.2 & 4 \\
\hline
\end{tabular}

\section{CONCLUSIONS}

The residual stresses induced due to quenching were experimentally investigated and were observed to be very high; if combined with the residual stresses induced during machining, manufacturing processes and externally applied loads can easily cause the failure of manufactured parts. The cold working compression reduces the residual stresses significantly and efficiently based on the compression ratio used for each aluminium alloy 2219 sample. The $2 \%$ compression ratio is observed to have the highest percentage of residual stress reduction. Relieving the residual stress is very important and necessary to enhance the better reliability of components under real service conditions. Therefore, it can be concluded that the cold working compression is a very efficient, effective and practically achievable method of reducing the high amount of residual stresses induced in aluminium 2219 components.

\section{ACKNOWLEDGEMENTS}

The authors are sincerely grateful to the management of the Central South University, School of mechanical and electrical engineering, Changsha, China, for providing all the required equipment used for the experiments carried out.

\section{REFERENCES}

[1] Şimşir, C., Gür, C. (2010). A Simulation of the quenching process for predicting temperature, microstructure, and residual stresses. Strojniški vestnik - Journal of Mechanical Engineering, vol. 56, no. 2, p. 93-103.

[2] Koç, M., Culp, J., Altan, T. (2006). Prediction of residual stresses in quenched aluminum blocks and their reduction through cold working processes. Journal of Materials Processing Technology, vol. 174, no. 1-3, p. 342-354, DOl:10.1016/j.jmatprotec.2006.02.007.

[3] Eslampanah, A.H., Aalami-aleagha, M.E., Feli, S., Ghaderi, M.R. (2015). 3-D numerical evaluation of residual stress and deformation due welding process using simplified heat source models. Journal of Mechanical Science and Technology, vol. 29, no. 1, p. 341-348, DOl:10.1007/s12206-014-1240-x.

[4] Urevc, J., Koc, P., Štok, B. (2009). Numerical simulation of stress relieving of an austenite stainless steel. Strojniški vestnik - Journal of Mechanical Engineering, vol. 55, no. 10, p. 590-598.

[5] Sim, W.-M. (2010). Challenges of residual stress and part distortion in the civil airframe industry. International Journal of Microstructure and Materials Properties, vol. 5, no. 4-5, p. 446-455, DOI:10.1504/IJMMP.2010.037621.

[6] Freborg, A., Ferguson, B., Li, Z. (2012). Predicting distortion and residual stress in a vacuum carburized and gas quenched 
steel coupon. Proceedings from the $6^{\text {th }}$ International Quenching and Control Distortion Conference, p. 22-33.

[7] Huang, X., Sun, J., Li, J. (2015). Effect of initial residual stress and machining-induced residual stress on the deformation of aluminium alloy plate. Strojniški vestnik Journal of Mechanical Engineering, vol. 61, no. 2, p. 131-137, DOl:10.5545/sv-jme.2014.1897.

[8] Ogrinec, P., Čepon, G., Boltežar, M. (2018). Introduction of welds into the dynamic model of laminated structures. Strojniški vestnik - Journal of Mechanical Engineering, vol. 64, no. 2, p. 73-81, D0I:10.5545/sv-jme.2017.4915.

[9] Lee, J., Hwang, J., Bae, D. (2018). Welding residual stress analysis and fatigue strength assessment at elevated temperature for multi-pass dissimilar material weld between alloy 617 and P92 steel. Metals and Materials International, vol. 24, no. 4, p. 877-885, Dol:10.1007/s12540-018-0086-7.

[10] Webster, G.A., Wimpory, R.C. (2001). Non-destructive measurement of residual stress by neutron diffraction. Journal of Materials Processing Technology, vol. 117, no. 3, p. 395399, DOl:10.1016/S0924-0136(01)00802-0.

[11] Wang, M., Liu, Y., Zan, T., Gao, X., Zhang, Y. (2016). Residual stress test and simulation of incremental hole-drilling method. $7^{\text {th }}$ International Conference on Mechanical and Aerospace Engineering, p. 257-261, DOI:10.1109/ICMAE.2016.7549546.

[12] Bae, D.H., Sohn, I.S., Hong, J.K. (2003). Assessing effects of residual stress on the fatigue strength of spot welds. Welding Journal, no. 1, p. 18-23.

[13] ASTM E837-13a (2013). Standard Test Method for Determining Residual Stresses by the Hole-Drilling StrainGage Method, West Conshohocken, ASTM International, DOI:10.1520/E0837-13A.

[14] Grant, P.V., Lord, J.D., Whitehead, P. (2006). The measurement of residual stresses by the incremental hole-drilling technique. Measurement Good Practice Guide, vol. 53, no. 2, p. 63.

[15] Liu, L., Wu, Y., Gong, H., Li, S., Kai W. (2019). Modification of constitutive model and evolution of activation energy on 2219 aluminum alloy during warm deformation process. Transactions of Nonferrous Metals Society of China, vol. 29, no. 3, p. 448-459, DOl:10.1016/S1003-6326(19)64954-X.

[16] Liu, L., Wu, Y., Gong, H., Li, S., Ahmad, A.S. (2018). A physically based constitutive model and continuous dynamic recrystallization behavior analysis of 2219 Aluminum alloy during hot deformation process. Materials, vol. 11, no. 8 , 1443, D0l:10.3390/ma11081443.

[17] Liu, L., Wu, Y., Gong, H. (2018). Effects of deformation parameters on microstructural evolution of 2219 Aluminum alloy during intermediate thermo-mechanical treatment process. Materials, vol. 11, no. 8, 1496, D0l:10.3390/ ma11091496.

[18] Prime, M.B., Newborn, M.A., Balog, J.A. (2003). Quenching and cold-work residual stresses in aluminum hand forgings: Contour method measurement and FEM prediction. Materials Science Forum, vol. 426-432, p. 435-440, D0I:10.4028/www. scientific.net/MSF.426-432.435.

[19] Žagar, S., Grum, J. (2011). Surface integrity after mechanical hardening of various Aluminium alloys. Strojniški vestnik Journal of Mechanical Engineering, vol. 57, no. 4, p. 334-344, D0l:10.5545/sv-jme.2010.092.

[20] Wang, Y., Yang, H., Zhang, C., Fei Yu, F. (2015). Analysis of the residual stress in zirconium subjected to surface severe plastic deformation. Metals and Materials International, vol. 21, no. 2, p. 260-269, D0l:10.1007/s12540-015-4195-2.

[21] ASM Handbook Committee (1990). Properties of wrought aluminum and aluminum alloys. Properties and Selection: Nonferrous Alloys and Special-Purpose Materials, ASM Handbook, vol. 2, p 62-122, ASM International, Materials Park, D0l:10.1361/asm.hb.v02.a0001060.

[22] Rendler, N.J., Vigness, I. (1966). Hole-drilling strain-gage method of measuring residual stresses. Experimental Mechanics, vol. 6, no. 12, p. 577-586, D0l:10.1007/ BF02326825.

[23] Masoudi, S., Amini, S., Saeidi, E., Eslami-Chalander, H. (2015). Effect of machining-induced residual stress on the distortion of thin-walled parts. The International Journal of Advanced Manufacturing Technology, vol. 76, no. 1-4, p. 597-608, D0I:10.1007/s00170-014-6281-x.

[24] Zhang, Q.Z., Shu, B.F., Chen, M.B., Liang, Q.B., Fan, C., Feng, Z.Q., Verlinden, P.J. (2015). Numerical investigation on residual stress in photovoltaic laminates after lamination. Journal of Mechanical Science and Technology, vol. 29, no. 2, p. 655-662, DOI:10.1007/s12206-015-0125-y.

[25] Kang, S.-W., Jang, B.-S., Song, H.-C. (2015). Residual stresses analysis of friction stir welding using one-way FSI simulation. Journal of Mechanical Science and Technology, vol. 29, no. 3, p. 1111-1121, D0I:10.1007/s12206-015-0223-x. 